\title{
Morphometry of the corpus callosum in monozygotic twins discordant for schizophrenia: a magnetic resonance imaging study
} Manuel F Casanova, Richard D Sanders, Terry E Goldberg, Llewellyn B Bigelow,
George Christison, E Fuller Torrey, Daniel R Weinberger

\begin{abstract}
The corpus callosum (CC) has been the focus of several morphometric studies of patients with schizophrenia, but the results of these studies have been contradictory. In an attempt to improve the reliability of morphometric measurements of the corpus callosum, a computerised image analysis system was used to measure the shape, area, thickness and length of the CC on magnetic resonance imaging (MRI) in 12 pairs of monozygotic twins discordant for schizophrenia (SC). No differences in CC area (anterior, middle, posterior thirds and total), length or vertical thickness of the CC body (at three levels) were demonstrated by $t$ test comparisons of the affected SC and unaffected twins. Statistical analysis of a Fourier expansion series suggested differences in shape between normal and SC cotwins in the second harmonic of the anterior and middle segments and effects of gender on posterior CC shape. These results fail to replicate previous findings of altered length, thickness and area in the schizophrenic CC, but implicate diseaserelated shape differences in the anterior and middle segment of the corpus callosum and gender-related differences in splenium shape. The disease-related shape distortion suggest ventriculomegaly rather than an intrinsic abnormality of the corpus callosum.
\end{abstract}

The idea that mental illness might be the result of faulty interhemispheric communication ${ }^{1}$ is ingrained within the term schizophrenia ("splitting of the psychic functions"). ${ }^{2}$ Although methodological handicaps have limited testing this hypothesis, a series of ingenious experiments by Sperry $^{3}$ in patients who had partial or total sectioning of the interhemispheric commisures, defined a "disconnection syndrome" characterised by abnormal responses to lateralised stimuli. In patients with schizophrenia, similar testing paradigms including abnormalities in tasks requiring matching of tachistoscopically presented verbal and nonverbal material, ${ }^{4}$ monaural asymmetries to complex speech comprehension, ${ }^{56}$ the transfer of learned information, ${ }^{78}$ the cross-localisation of tactile stimulation, ${ }^{9}$ and alterations in $\mathrm{EEG}^{10}$ and evoked potential studies ${ }^{11}$ have suggested an impairment of interhemispheric communication. Since the corpus callosum (CC) provides the major conduit for association bundles connecting the hemispheres, there have been several morphometric studies searching for abnormalities of this structure in schizophrenic patients (tables 1 and 2). Results of these studies have been contradictory. This has also been true of attempts to relate CC morphology to handedness, gender, age and brain size. ${ }^{13-15}$

Because human CC morphology is highly variable, ${ }^{1415}$ and the determinants of its size and shape are still unknown, optimally matched controls are of utmost importance in eliminating confounding variables. The present MRI study compared measures of CC size and shape in twelve schizophrenic patients and their unaffected monozygotic cotwins. Quantitative analyses of CC shape was employed for the first time in schizophrenia. Given that the experimental and control groups were matched completely for inherited genome and partially for pre- and postnatal environment, any differences in CC gross morphology might represent pathological features inherent to the schizophrenic syndrome.

\section{Methods}

Patients

The patients were pairs of identical twins discordant for schizophrenia recruited from all parts of the United States and Canada under the project Biological Markers in Discordant Monozygotic Twins. Measures taken to insure that recruited twins were in fact identical included examination of school

Table 1 Necropsy studies of callosal gross morphology in schizophrenia.

\begin{tabular}{|c|c|c|c|c|}
\hline Study & Patient & Control & Thickness & Area \\
\hline $\begin{array}{l}\text { Rosenthal and Bigelow }{ }^{43} \\
\text { Bigelow et } a l^{44} \\
\text { Brown et a } l^{45} \\
\text { Machiyama et } a l^{46}\end{array}$ & $\begin{array}{l}10 \text { Langfeldt "bad prognosis" } \\
21 \text { RDC onset < } 30 \text { years } \\
26 \text { Feighner } \\
5 \text { ?criterion }\end{array}$ & $\begin{array}{l}10 \text { mixed psychiatric } \\
14 \text { psychiatric, } 13 \text { neurologic } \\
29 \text { affective } \\
7 \text { normal }\end{array}$ & $\begin{array}{l}>\text { body } \\
>\text { body (anterior, and middle average) } \\
\text { NS (one level) } \\
>\text { body (anterior only) }\end{array}$ & $\overline{\bar{z}}$ \\
\hline
\end{tabular}

- Not specified

NS Not significant

$>$ Increased 
Table 2 MRI studies of callosal morphology in schizophrenia.

\begin{tabular}{|c|c|c|c|c|c|}
\hline Study & Patients & Controls & Area & Thickness & Length \\
\hline 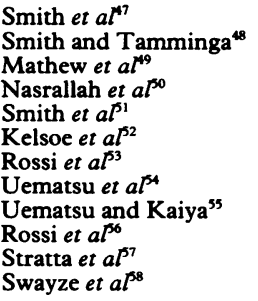 & $\begin{array}{l}9 \text { RDC } \\
23 \text { RDC } \chi \\
18 \text { DSMIII } \\
28 \text { DSMIII } \\
29 \text { DSMIII @ } \\
24 \text { DSMIII } \\
12 \text { \#\# } \\
24 \text { DSMIII } \\
40 \text { DSMIII } \\
15 \text { DSMIII } \\
20 \text { DSMIII } \\
54 \text { \#\# }\end{array}$ & $\begin{array}{l}5 \text { normal } \\
17 \text { normal } \\
18 \text { normal } \\
41 \text { normal } \\
21 \text { normal } \\
14 \text { normal } \\
12 \text { normal } \\
7 \text { normal } \\
17 \text { normal } \\
15 \text { normal } \\
20 \text { normal } \\
48 \text { manic }\end{array}$ & $\begin{array}{l}\text { NS } \\
\text { NS } \\
\text { NS } \\
> \\
\text { NS } \\
\text { NS } \\
< \\
>@ @ \\
>@ @ \\
< \\
<\# \\
\text { NS }\end{array}$ & $\begin{array}{l}\overline{N S} \\
\overline{>} \star \star \\
\text { NS } \\
\text { NS } \\
\overline{\text { NS }} \\
\overline{\text { NS }}\end{array}$ & $\begin{array}{l}\overline{-} \\
>^{\star} \\
\text { NS } \\
\overline{-} \\
\overline{\text { NS }} \\
\text { NS } \\
\overline{-}\end{array}$ \\
\hline
\end{tabular}

$\chi$ Included two cases of acute schizophrenia and one schizoaffective psychosis.

* Using the data given in the article, the difference is not statistically significant.

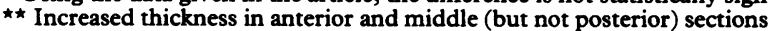

@ Includes schizoaffective and schizophreniform patients.

@@ Increased only in the ratio of the anterior third to the midsagittal brain area.

\# Only the ratio of CC to midsagittal brain area is reported.

\# Diagnostic criteria not specificed.

$>$ Increased.

$<$ Decreased.

pictures, use of a questionnaire ${ }^{16}$ and profiles of human lymphocyte antigen and 19 red blood cells groupings. In all, there were twelve discordant pairs, consisting of five males and seven female pairs.

All twins had a standardised structured diagnostic interview (SCID) ${ }^{17}$ to establish DSM III-R diagnoses. The members diagnosed with schizophrenia were subtyped as follows: eight undifferentiated, two paranoid, and two residual. Nine of the cotwins without schizophrenia were not given psychiatric diagnosis. Three met criterias for drug abuse (sedative/hypnotic, cannabis, and sympathomimetic dependence), which had ceased several years before the study. The ages of the twins ranged from 25 to 44 years with a mean of 32.6 years. The twins with schizophrenia had a duration of illness (time since initial psychiatric referral) ranging from two to 24 years with a mean of 10.3 years. The affected member had had three to 28 admissions to hospital, with a mean of 8.7 admissions. All pairs had been discordant for at least five years (range 5-24 years) with a mean of 10.4 years; this makes it unlikely that these twins will become concordant in the future. All affected individuals were taking neuroleptic medication at the time of testing, and three had received electroconvulsive therapy in the past. Three of the twelve pairs had a first or second degree relative with a definite or probable diagnosis of schizophrenia.

The perinatal and postnatal histories of the twins were closely examined for evidence of organic factors which might result in cerebral abnormalities. One affected twin had what was probably a postnatal encephalitis and one control twin had pulmonary stenosis that was corrected with surgery. No other differences between the twins could be explained by known potential causes of cerebral abnormalities.

\section{Magnetic resonance imaging}

All twins were scanned in the same General Electric 1.5 tesla scanner. Contiguous sagittal slices $5 \mathrm{~mm}$ thick were $T 1$ weighted with a recovery time (TR) of $800 \mathrm{~ms}$. Four excitations were used in most cases, however, two were used to shorten scanning time for patients who had difficulties tolerating the procedure. This was necessary for both members of three pairs and one member of another pair. Selection of the midsagittal level in our study was based on the visualisation of the crest of the gyri in the mesial aspect of the hemispheres.

\section{Computerised image analysis}

Digitisation of MRI scans was performed with a LOATS computerised image analysis system. Illumination was maximised and referenced for correction of individual scans. Films were placed over a light box and digitised with a DAGE 68 camera interfaced to an IBM PC AT via an expansion chassis. A single digitisation mode was selected. The image was enlarged $2 \cdot 8 \times$, contrast enhanced, and plotted on a monitor for visual inspection. The resulting resolution (that is, the actual length of the image across the monitor screen divided by the number of pixels across the same axis) was $0.31 \mathrm{~mm}$. All measurements were calibrated against the horizontal metric scale of the MRI scans. The corpus callosum was divided into thirds with a Gerber variable scale and each individual segment, as well as the whole corpus callosum, was manually outlined with an electronic mouse and magnetic tablet using a "polygon function". Thickness, defined as the longest vertical height, was measured in pixel units. The corpus callosum length, defined as the distance from the splenium to the genu, was also measured in pixel units.

Shape analysis ${ }^{18-20}$ was performed by outlining the periphery of the desired structure with a "polygon function". The centroid was then determined in a Cartesian coordinate system by projecting vectors from candidate points to the boundary of the figure. The vectors tracked the boundary in a clockwise fashion. Moments of the vectors with respect to the $\mathbf{x}$ and $y$ axis were obtained, those belonging to each axis added and then divided by the area of the structure. Since the clockwise movement of the vector returned to the original starting point, it represents a repeating function that can be described by a Fourier expansion series. This was achieved by transforming the points defining the periphery of the object into polar coordinates and expressing the resulting contour in terms of an addition series of either sine or cosine functions. In this series, each one of the harmonic amplitudes defines a weighting factor which characterises the contributions of different and successively more complex geometrical figures to the shape of the object. All the harmonic amplitudes were normalised against the 0 harmonic. The phase angles for the different harmonics served as a measure of rotational orientation for each of the geometrical shapes defined by the particular harmonics.

\section{Statistıcs}

Area analyses were made by match-pair $t$ tests. For nonparametric tests of harmonics, 
Table $3 T$ test analysis of corpus callosum length, thickness, and area.

\begin{tabular}{lrrll}
\hline & $C$ & $S C$ & $t$ & $p$ \\
\hline Length & $71.5(4.30)$ & $71.91(3.65)$ & 0.75 & 0.46 \\
Anterior thickness & $4.38(0.94)$ & $4.63(0.67)$ & 0.25 & 0.81 \\
Middle thickness & $4.99(0.76)$ & $4.63(0.94)$ & 0.19 & 0.85 \\
Posterior thickness & $4.47(1.11)$ & $4.55(1.51)$ & 0.15 & 0.88 \\
Posterior area & $1.54(0.41)$ & $1.59(0.43)$ & 0.29 & 0.77 \\
Middle area & $0.96(0.25)$ & $0.97(0.30)$ & 0.61 & 0.94 \\
Anterior area & $1.52(0.47)$ & $1.54(0.49)$ & 0.13 & 0.90 \\
Whole area & $4.08(1.08)$ & $4.13(1.15)$ & 0.09 & 0.92 \\
Hemisphere area & $71.43(1.79)$ & $69.87(6.57)$ & 0.57 & 0.57 \\
\hline
\end{tabular}

analysis of the groups utilised rank order tests. For parametric tests, scores were square root transformed because the distribution of shape scores was skewed.

\section{Results}

Areas of the anterior, middle, and posterior parts of the corpus callosum were compared between groups by matched pair $t$ test. No differences emerged (table 3 ). The hemispheric areas in the saggital plane also did not differ between the groups. The length of the corpus callosum was not significantly different between the groups. No area comparison attained significance by matched pair $t$ test analysis.

Shape analysis utilising harmonics was applied. The overall shape of the corpus callosum did not differ significantly (non- parametric Kruskal Wallis rank order analysis) between the groups by harmonics 1 , 2,3 , or 4 (table 4). On further analysis, the second harmonic (the predominant determinant of shape in this study) displayed variations with diagnosis that approached statistical significance in the anterior and middle segments by Kruskal Wallis tests $(p=0.057$ and $p=0.061$ respectively) (table 4). Matched pair $t$ test analysis supported these results. In the middle segments a trend for between pair differences was found for harmonic 2 $(p=0.09)$. A similar trend was found in the anterior segment for harmonic $2(p=0.09)$.

Significant sex difference in the shape of the corpus callosum were also found in harmonics 1 and 3 in the posterior segment, but not in the dominant second harmonic by Kruskal Wallis tests (table 4). Sex differences were not discerned in the anterior or middle segments.

To further examine the influence of diagnosis and sex, as well as their combined influence (for example, diagnosis $\times$ sex interaction), MANOVAs were performed on the square root transformed harmonics (table 5). In the anterior segment a trend for a main effect of diagnosis was present as well as a significant interaction of diagnosis and sex (notably in harmonics 2 and 4). In the middle segment a trend for a significant interaction of

Table 4 Rank order harmonic amplitude analysis by diagnosis and gender

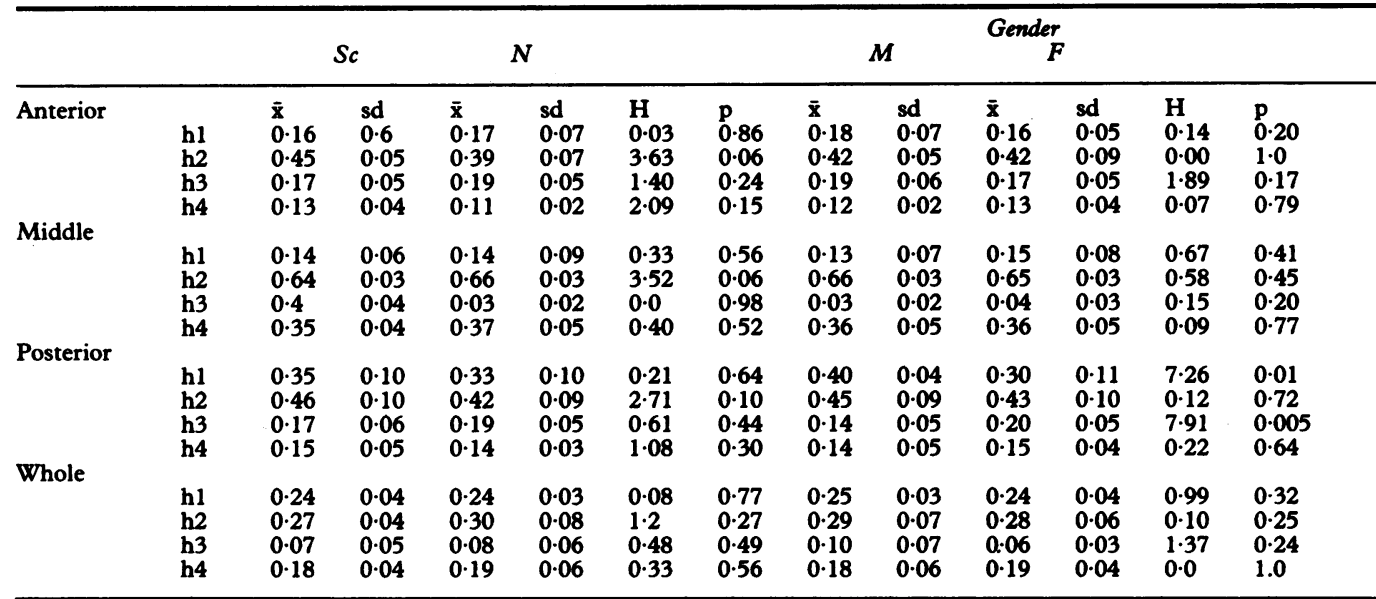

h1-4; harmonic amplitudes $1-4$.

Table 5. Multivariate analysis of variance (MANOVA) of diagnosis and sex on the harmonic amplitudes

\begin{tabular}{|c|c|c|c|c|c|c|}
\hline & \multirow{2}{*}{\multicolumn{2}{|c|}{ Manova Main Effect }} & \multicolumn{4}{|c|}{ Univariate Contrasts $P$} \\
\hline & & & $h 1$ & $h 2$ & $h 3$ & $h 4$ \\
\hline $\begin{array}{l}\text { Anterior } \\
\text { Dx } \\
\text { Sex } \\
\text { Dx \& Sex }\end{array}$ & $\begin{array}{l}\text { Wilks } \\
\text { Wilks } \\
\text { Wilks }\end{array}$ & $\begin{array}{l}\mathbf{L}=0.66, p=0.11 \\
\mathbf{L}=0.91, p=0.77 \\
\mathbf{L}=0.41, p=0.003\end{array}$ & $\bar{z}$ & $\frac{\bar{z}}{\text { yes }}$ & $\bar{z}$ & $\bar{z}$ \\
\hline $\begin{array}{l}\text { Middle } \\
\text { Dx } \\
\text { Sex } \\
\text { Dx \& Sex }\end{array}$ & $\begin{array}{l}\text { Wilks } \\
\text { Wilks } \\
\text { Wilks }\end{array}$ & $\begin{array}{l}L=1.04, p=0.42 \\
L=0.93, p=0.86 \\
L=2.38, p=0.09\end{array}$ & $\bar{z}$ & $\bar{z}$ & $\overline{\bar{z}}$ & $\bar{z}$ \\
\hline $\begin{array}{l}\text { Posterior } \\
\text { Dx } \\
\text { Sex } \\
\text { Dx \& Sex }\end{array}$ & $\begin{array}{l}\text { Wilks } \\
\text { Wilks } \\
\text { Wilks }\end{array}$ & $\begin{array}{l}L=0.89, p=0.72 \\
L=0.59, p=0.05 \\
L=0.98, p=0.98\end{array}$ & $\overline{\text { yes }}$ & $\bar{z}$ & $\overline{\text { yes }}$ & E \\
\hline
\end{tabular}

h1-4; harmonic amplitudes 1-4

Wilks; Wilks Lambda test for significance. diagnosis and sex was present while in the posterior segment a significant main effect for sex was present (notably in harmonics 1 and 3 ).

\section{Discussion}

This study compared the morphology of the CC of normal and schizophrenic cotwins and found no difference in any of the indices of CC area, length and thickness. Shape analysis revealed alterations in the secondary harmonics of the posterior CC of the affected twin, but the minor contributions of these harmonics to the overall shape of the segment renders them difficult to interpret. ${ }^{1821}$ Our study also disclosed differences in the dominant second harmonic of the anterior and middle segments. 
Figure 1 Anatomical sketches of the genu $(g)$ and splenium $(s)$ of the corpus callosum in our patient population. The spatial relation between these anatomical structures have been preserved and drawn to proportion. Shape analysis based on a Fourier expansion series suggested no major differences between these subdivisions of the corpus callosum in schizophrenic patients and the controls.

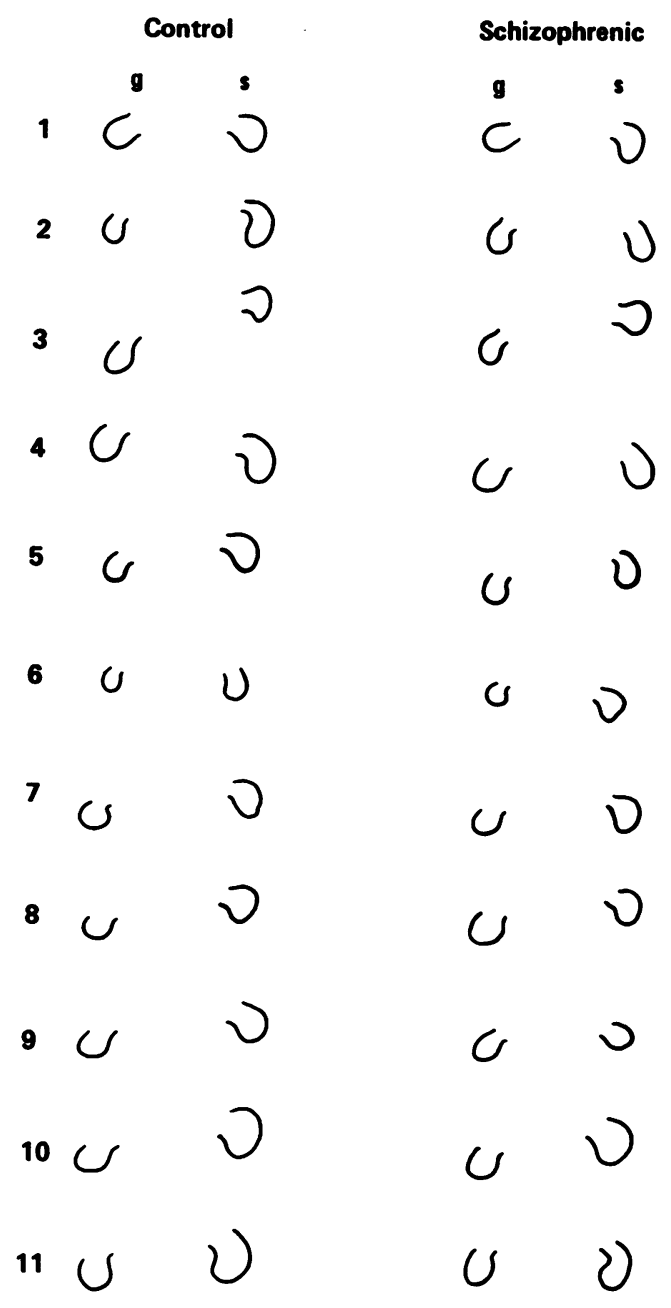

The necessary inclusion of two artificial linear borders in the middle segment, (that is, two cuts were made through the corpus callosum to divide it into equal thirds) would, if anything, tend to reduce the shape variability in this segment. These differences suggest that a relationship may exist between CC gross morphology for this segment and schizophrenia in identical twins discordant for the syndrome (fig 1). Analysis of the harmonic amplitude pattern reveals that the distortion of the $\mathrm{CC}$ represents an upward bowing which is magnified in its middle-most segment (fig 2). This pattern is characteristic of hydrocephalus, ${ }^{22}$ and may be related to the finding of ventricular enlargement in schizophrenia. ${ }^{23}$ Thus our findings suggest that the observed distortion is secondary to ventricular enlargement rather than an intrinsic abnormality of the CC itself.

In a study of the mophology of the CC in 450 midline sagittal MRI scans, McLeod et al ${ }^{24}$ differentiated congenital from acquired abnormalities based on clinical information. Acquired changes resulting in hydrocephalus manifested significant differences in the length and thickness of the corpus callosum. The absence of similar changes in our series suggests that the hydrocephalic process observed in schizophrenic patients is more typical of congenital origin. Another possibility is that the majority of acquired cases reported by McLeod et $a l^{24}$ were caused by obstruction of the cerebrospinal flow leading to pressure atrophy of the corpus callosum. Unfortunately, McLeod et $a{ }^{24}$ did not differentiate cases according to their underlying pathophysiology.

Although this study was not designed to study sex differences, it allowed the opportunity to investigate claim ${ }^{25-27}$ that the shape of the splenium varies with gender. Two of the harmonics of the posterior third of the CC (including but not limited to the splenium) showed highly significant differences attributable to gender, but the MANOVA comparison (incorporating all four harmonics) was not significant. Thus, these data partially support the existence of some minor sex differences in the shape of the caudal CC. Harmonic shape analysis should be applied to larger groups of normal subjects to study this phenomenon further.

Males had longer CC than females. This did not appear to be attributable to brain size differences, as length and hemisphere area were not correlated. None of the four previous studies that examined this variable in terms of gender ${ }^{14252829}$ found a difference. Consistent with other studies of CC and gender, area measurements did not differ; this held even when these were "corrected" for brain size (that is, divided by mid-sagittal area of the right hemisphere), which was predictably larger in the males. ${ }^{3031}$

The corpus callosum connects in an orderly fashion homologous cortical regions of the two hemispheres. Fibres joining parts of the frontal lobes project through the so-called forceps minor which funnels into the callosal genu, while occipital radiations pass through the splenium. ${ }^{32}$ In our study, we found no significant area differences in the anterior part of the corpus callosum. Conformational changes in this segment were attributed to ventriculomegaly. Given the large number of studies reporting a dysfunction of the frontal lobes in schizophrenia, ${ }^{33-36}$ our results do not support the notion that abnormalities in this region, if present, are the result of aberrant projections joining both frontal cortices. Rather, frontal lobe dysfunction in schizophrenia is more likely to manifest abnormalities in other areas. ${ }^{34}$

As the preponderant corticocortical tract, the $\mathrm{CC}$ is a reasonable first site of investigation for those seeking an anatomic counterpart to the lack of connections between expressed thoughts of schizophrenic patients emphasised by Bleuler ${ }^{2}$ and prominent in Schneider's ${ }^{37}$ first-rank symptoms. Recent studies have suggested that schizophrenic symptomatology may be, in part, the manifestation of a disconnection syndrome. It should be noted, however, that surgically sectioned CC patients or children with lesions of the CC do not develop schizophreniform symptoms. ${ }^{36-10}$ Similarly, there has been only one case report of schizophrenia associated with complete agenesis of the corpus callosum. ${ }^{41}{ }^{42}$ Our study suggests that if a defect of interhemispheric integration exists in schizophrenia, its structural counterpart is not detectable at the macroscopic level. 


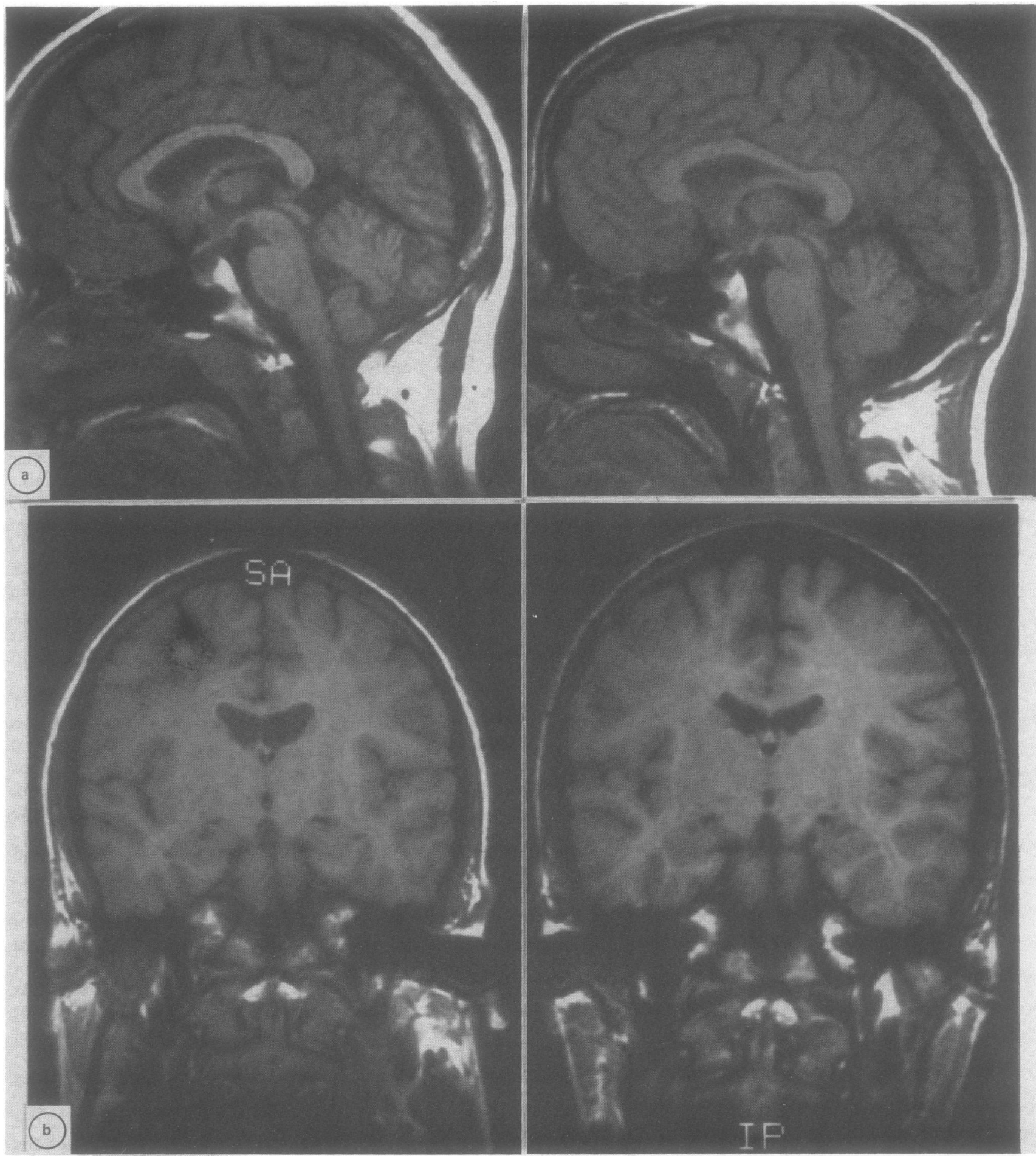

Figure 2 Midsagittal sections of the brain reveal an upward bowing of the corpus callosum of a patient with schizophrenia $(A)$ compared with his asymptomatic cotwin $\left(A^{\prime}\right)$. Coronal sections of the same subjects (B-schizophrenic, $B^{\prime}$-normal cotwin) suggest that the bowing is related to ventriculomegaly.

This study was supported by NIMH grant No MH 41176.

1 Green P, Glass A, O'Callaghan MAJ. Some implications of abnormal hemisphere interaction in schizophrenia. In: Gruzelier JH, Flor-Henry P, eds. Hemisphere asymmetries of function in psychopathology. Amsterdam: Elsevier, 1979:431-48.

2 Bleuler E. Dementia praecox or the group of schizophrenias. (Trans J Zinkin). New York: International Universitie Press, 1908:9.

3 Sperry RW, Gazzaniga MS, Bogen JE. Interhemispheric relationships. The neocortical commisures: syndromes of hemispheric dysconnection. In: Vinken PJ, Bruyn GW, eds. Handbook of clinical neurology, Vol 4, chap 14. Amsterdam: Elsevier, 1969

4 Beaumont J, Dimond S. Brain disconnection and schizophrenia. Br J Psychiatry 1973;123:661-2.

5 Green $P$, Hallett S, Hunter M. Abnormal interhemispheric integration and hemispheric specialisation in schizointegration and hemispheric specialisation in schizophrenics and high-risk children. In: Flor-Henry P, Gruzelier JH, eds. Laterality and

6 Green P, Kotenko V. Superior speech comprehension in schizophrenics under monaural versus binaural listening conditions. J Abnorm Psychol 1980;89:399-408.

7 Green P. Defective interhemispheric transfer in schizophrenia. J Abnorm Psychol 1978;87:472-80.

8 Hatta T, Yamamoto M, Kawabata Y. Functional hemispheric differences in schizophrenia: Interhemispheric transfer deficit or selective hemispheric dysfunction? Biol Psychiatry 1984;131:892-900.

9 Dimond SJ, Scammel RE, Pryce IG, et al. Some failures of international and cross-lateral transfer in chronic schizophrenia. J Abnorm Psychiatry 1980;89:505-9.

10 Shaw JC, Brookes S, Colter N, O'Connor K P. A comparison of schizophrenic and neurotic patients using EEG power and coherence spectra. In: Gruzelier JH, Florpowry $\mathrm{P}$, eds. Hemisphere asymmetries of function in psychopathology. Amsterdam: North Holland Biomedical, 
1979:527-84.

11 Buchsbaum MS, Carpenter WT, Fedio P, et al. Hemisphere differences in evoked potential enhancement by selective differences in evoked potential enhancement by selective phrenic, affective and post-temporal lobectomy patients. In: Gruzelier JH, Flor-Henry P, eds. Hemispheres asymIn: Gruzelier JH, Flor-Henry $\mathrm{P}$, eds. Hemispheres asym-
metries of function in psychopathology. Amsterdam: North metries of function in psychopathology.

12 Gulman NC, Wildschoidtz G, Orback K. Alternations in interhemispheric through corpus callosum in chronic schizophrenia. Biol Psychiatry 1982;17:585-94.

13 Kertesz A, Polle M, Howell J, Block SE. Cerebral dominance, sex, and collosal size in MRI. Neurology 1987; 32:1335-8.

14 Byne W, Bleier R, Houston L. Variations in the human corpus callosum do not predict gender: a study using magnetic resonance imaging. Behavioral Neuroscience 1988;102(2):222-7.

15 Demeter S, Ringo JL, Doty RW. Morphometric analysis of the human corpus callosum and anterior commissure. the human corpus callosum and
Human Neurobiol 1988;6:219-26.

16 Cederlof R, Friberg L, Jonson E, et al. Studies on similarity diagnosis in twins with the aid of mailed questionnaires. Acta Genet 1961;11:338-62.

17 Spitzer RL, Williams JB, Gibbon M, First MB. Instruction manual for the structured clinical interview for DSM III-R (SCID, 4/1/88 Rev). New York: Biometric Research Department, New York State Psychiatric Institute, 1988.

18 Christison GW, Casanova MF, Weinberger DR, et al. A quantitative investigation of hippocampal pyramidal cell size, shape and variability of orientation in schizophrenia. Arch Gen Psychiatry, 1989;46:1027-32.

19 Lloyd DG, Loats HL, Price DL, et al. Computer aided morphometric data collection, mapping, and analysis for morphometric data collection, mapping, and analysis

20 Loats HL, Lloyd DG, Pittenger M, et al. Biomedical image analysis applications. In: Corklin JJ, Swenberg CE, eds. Imaging techniques in biology and medicine, California: Academic Press, 1988:1-75.

21 Casanova MF, Goldberg TE, Weinberger DR, Kleinman JE, Rawlings R, Suddath R, Daniel DG: Shape analysis of the temporal lobes of schizophrenic patients. Society for Biological Psychiatry, Forty-third Annual Convention, 4 8 May, 1988.

22 Peterson, HO, Kieffer SA: Neuroradiology. In: Baker AB, Baker LH, eds. Clinical Neurology (Vol 1). New York: Harper and Row, 1-290.

23 Suddath RL, Casanova MF, Goldberg TE, Daniel DG, Kelsoe JR, Weinberger DR. Temporal lobe pathology in schizophrenia: A quantitative magnetic resonance imagschizophrenia: A quantitative magnetic reson

24 McLeod NA, Williams JP, Machen B, Lum GB. Normal and abnormal morphology of the corpus callosum. Neurology 1987;37:1240-2.

25 deLacoste-Utamsing MC, Holloway RL. Sexual dimorphism in the human corpus callosum. Science 1982; 216:1431-2.

26 Holloway RL, deLacoste MC. Sexual dimorphism in the human corpus callosum: an extension and replication study. Human Neurobiol 1986;5:87-91.

27 Yoshii F, Barker W, Apicella A, et al. Measurements of the corpus callosum on magnetic resonance scans: effects of age, sex, handedness and disease (abst). Neurology 1986;36(suppl 1):133.

28 Nasrallah HA, Andreason NC, Coffman JA, et al. A controlled magnetic resonance imaging study of corpus callosum thickness in schizophrenia. Biol Psychiatry 1986;21:274-82.

29 Weber G, Weis $\mathbf{S}$. Morphometric analysis of the human corpus callosum fails to reveal sex-related differences. $J$ Hirnforsch 1986;27(2):237-40.

30 Holloway RL. Within-species brain-body weight variability: A reexamination of the Danish data and other primate species. Am J Phys Anthropol 1980;53:109-21.

31 Witelson SF. The brain connection: the corpus callosum is larger in left-handers. Science 1985;229:665-8.

32 Warwick R, Williams PL. Gray's Anatomy, (35th $\mathrm{Br}$ ed). Philadelphia: Saunders WB, 1973:966.

33 Zec RF, Weinberger DR. Brain areas implicated in schizophrenia: a selective overview. In: Nasarallah HA, Wein-
berger DR, eds. The neurology of schizophrenia. North berger DR, eds. The neur

34 Weinberger DR, Berman KF, Zec RF. Physiologic dysfunction of the dorsolateral prefrontal cortex in schizophrenia: I. Regional cerebral blood flow evidence. Arch Gen
Psychiatry 1986;43:114-24.

35 Berman KF, Zec RF, Weinberger DR. Physiologic dysfunction of dorsolateral prefrontal cortex in schizophrenia: II. Role of neuroleptic treatment, attention, and mental Role of neuroleptic treatment, attention,
effort. Arch Gen Psychiatry 1986;43:126-35.

36 Weinberger DR, Berman KF, Illowsky BP. Physiologic dysfunction of the dosolateral prefrontal cortex in schizophrenia: III. A new cohort and evidence for a monoaminergic mechanism. Arch Gen Psychiatry 1988;45:609-15.

37 Schneider K. Clinical Psychopathology. New York: Grune and Stratton, 1959.

38 Wade JB, Taylor MA. Interhemispheric transfer in schizophrenia and

39 Jeeves MA. Age related effects of agenesis and partial sectioning of the neocortical commissures. In: van Hof MW, Mohn G, eds. Developments in neuroscience: functional recovery from brain damage (Vol 13). North Holland: tional recovery fron

40 Jeeves MA. Functional and neuronal plasticity: The evidence from callosal agenesis. In: Almli CR, Finguer S, eds. Early brain damage vol I: research orientations and clinical observations. New York: Academic Press, 1984:233-52.

41 Lewis SW, Revely MA, David AS, et al. Agenesis of the corpus callosum and schizophrenia: a case report. Psychol Med 1988;18:341-7.

42 Andreasen NC, Elrhardt J, Yuh W, Swayze V, Ziebell S, Cohen G: Magnetic resonance imaging in schizophrenia: an update. In: Schulz SC, Tamminga CA, eds. Schizophrenia Scientific Progress. New York: Oxford University prenia Scientific

43 Rosenthal R, Bigelow LB. Quantitative brain measurements in chronic schizophrenia. $B r J$ Psychiatry 1972;121: $259-64$.

44 Bigelow LB, Nasrallah HA, Rauscher FP. Corpus callosum thickness in chronic schizophrenia. Br J Psychiatry 1983;142:284-7.

45 Brown R, Colter N Corsellis JAN, et al.Postmortem evidence of structural brain changes in schizophrenia. Arch Gen Psychiatry 1986;43:36-42.

46 Machiyama Y, Watanabe Y, Machiyama R. Neuroanatomical studies of the corpus callosum in schizophrenia: Evidence of aberrant interhemispheric fibre connection. In: Takahas R Flor-Henry P, Gruzelier J, Niwa S, eds. Cerebral dynamics, laterality and psychopathology. New York: Elsevier, 1987:411-12.

47 Smith RC, Calderon M, Ravichandran GK, et al. Nuclear magnetic resonance in schizophrenia: a preliminary study. Psychiatry Res 1984;12:137-47.

48 Smith RC, Tamminga CA. Brain imaging in psychiatry: New developments. Psychopharmacol Bull 1985;21: 588-94.

49 Mathew RJ, Partain CL, Prakash R, et al. A study of the septum pellucidum and corpus callosum in schizophrenia

50 Nith MR imaging. Acta Psychiatr Scand 1985;72:414-21. cher FP. A histological study of the corpus callosum in chronic schizophrenia. Psychiatry Research 1983;8: 251-60.

51 Smith RC, Baumgartner R, Calderon M. Magnetic resonance imaging studies of the brains of schizophrenic patients. Psychiatry Res 1987;20:33-46.

52 Kelsoe JR, Cadet JL, Pickar D, Weinberger DR. Quantitative neuroanatomy in schizophrenia. Arch Gen Psychiatry 1988;45:533-41.

53 Rossi A, Stratta P, Casacchia M, et al. Corpus callosum in schizophrenia (letter). Biol Psychiatry 1987;22:1043.

54 Uematsu M, Kaiya H, Eguchi K, et al. Mid-sagittal brain feature of schizophrenia by MRI with special references to family history. In: Takahashi R, Flor-Henry P, Gruzelier $\mathrm{J}$, Niwa $\mathrm{S}$, eds. Cerebral dynamics, laterality and psychopathology. New York: Elsevier, 1987:389-97.

55 Uematsu $M$, Kaiya $H$. The morphology of the corpus callosum in schizophrenia: An MRI study. Schizophr Res 1988;1:391-8.

56 Rossi A, Stratta P, Galluci M, et al. Brain morphology in schizophrenia by magnetic resonance imaging (MRI) Acta Psychiat Scand 1988;77:741-5.

57 Stratta $P$, Rossi A, Galluci M, et al. Hemispheric asymmetries and schizophrenia: A preliminary magnetic reson-

58 Swayze VW, Andreason NC, Ku JS, Alliger R. The corpus callosum in schizophrenia and mania: A controlled MRI study. Schizophr Res 1989;2(1-2):130. 